\title{
Catalytic trifluoromethylation of iodoarenes by use of 2-trifluoromethylated benzimidazoline as trifluoromethylating reagent
}

\author{
Tatsuhiro Uchikura, Nanami Kamiyama, Taisuke Ishikawa and Takahiko Akiyama*
}

\author{
Letter \\ Address: \\ Department of Chemistry, Faculty of Science, Gakushuin University, \\ Mejiro, Toshima-ku, Tokyo, 171-8588, Japan \\ Email: \\ Takahiko Akiyama* - takahiko.akiyama@gakushuin.ac.jp \\ * Corresponding author \\ Keywords: \\ benzimidazoline; catalysis; copper; fluorine chemistry; \\ trifluoromethylation
}

Open Access

\author{
Beilstein J. Org. Chem. 2020, 16, 2442-2447. \\ https://doi.org/10.3762/bjoc.16.198 \\ Received: 31 July 2020 \\ Accepted: 15 September 2020 \\ Published: 30 September 2020 \\ This article is part of the thematic issue "Organo-fluorine chemistry V". \\ Guest Editor: D. O'Hagan \\ (C) 2020 Uchikura et al.; licensee Beilstein-Institut. \\ License and terms: see end of document.
}

\begin{abstract}
The trifluoromethylation of iodoarenes was accomplished by use of a 2-trifluoromethylbenzimidazoline derivative as the trifluoromethylating reagent and a catalytic amount of $\mathrm{Cu}(\mathrm{I})$ in the presence of 2,2'-bipyridyl as the ligand. Through a mechanistic study, we found that the oxidative addition of the iodoarene to the $\mathrm{Cu}(\mathrm{I})-\mathrm{CF}_{3}$ species is the rate-determining step.
\end{abstract}

\section{Introduction}

The introduction of a trifluoromethyl group is one of the most attractive reactions in drug discovery [1,2]. In the past decade, trifluoromethylation reactions of aryl halides in the presence of transition-metal complexes were reported [3-21]. $\mathrm{CuCF}_{3}$ is a useful species for the trifluoromethylation of aryl halides and there are a number of precursors of $\mathrm{CuCF}_{3}$ for trifluoromethylation reactions. In contrast, the catalytic generation of $\mathrm{CuCF}_{3}$ was less investigated [15-21]. For example, $\mathrm{R}_{3} \mathrm{SiCF}_{3}$, a fluoral derivative, and trifluoroacetates were employed as precursors of $\mathrm{CuCF}_{3}$ species for the catalytic trifluoromethylation of iodoarenes (Figure 1a) and the development of novel types of trifluoromethylating reagents is still desired. We have recently reported the trifluoromethylation of iodoarenes by use of 2-aryl-2-trifluoromethylbenzimidazoline as the trifluoromethylating reagent in the presence of 3 equiv of a copper salt [22]. The benzimidazoline derivatives could be readily prepared from relatively cheap materials, namely, trifluoromethylacetophenone and phenylenediamine derivatives (Figure 1b). Herein we report a catalytic trifluoromethylation of iodoarenes by use of benzimidazoline derivatives in the presence of a catalytic amount of copper salts and a bipyridyl ligand (Figure 1c).

\section{Results and Discussion}

We first investigated the reaction conditions by use of $p$-iodonitrobenzene (1a) and 2-phenyl-2-trifluoromethyl-1methylbenzimidazoline (2) (Table 1). Using 3 equiv of $\mathrm{CuI}$ gave 4-trifluoromethyl-1-nitrobenzene (3a) quantitatively, as 
(a) examples of trifluoromethylating reagents

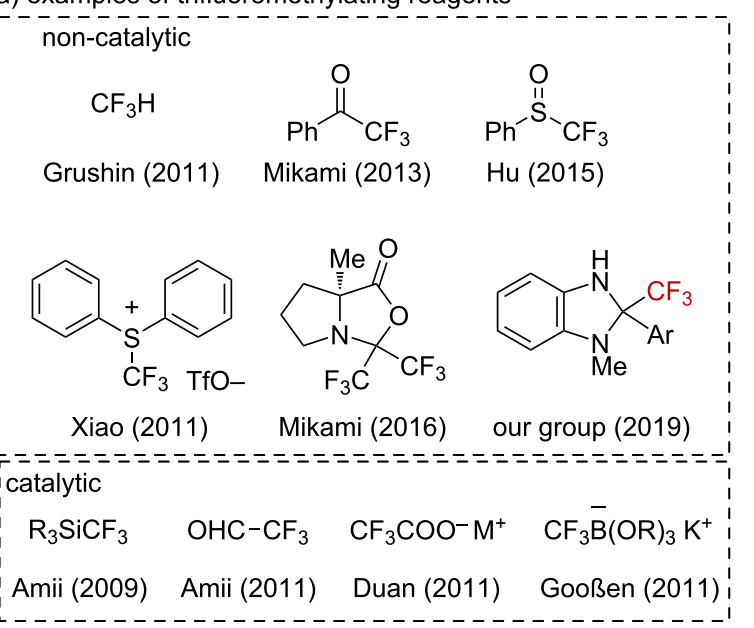

(b) synthesis of 2-trifluormethylbenzimidazoline<smiles>O=C(Br)C(F)(F)F</smiles><smiles>CNc1ccccc1N</smiles>

cat. Lewis acid<smiles>CN1c2ccccc2NC1(Br)C(F)(F)F</smiles>

easily available from corresponding ketones

(c) this work catalytic trifluoromethylation using benzimidazoline<smiles>[R]CC(CC)C(Cl)C1Nc2ccccc2NC1([Al])C(F)(F)F</smiles>
up to $93 \%$ yield

Figure 1: Trifluoromethylation of aryl halides.

Table 1: Screening for reaction conditions ${ }^{a}$.

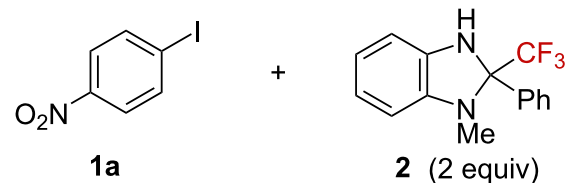

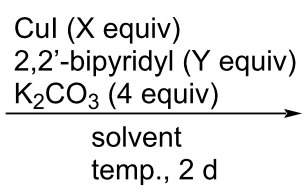

$\mathrm{O}_{2} \mathrm{CF}_{3}$

$3 a$

\begin{tabular}{|c|c|c|c|c|c|}
\hline entry & $x$ & $\mathrm{Y}$ & solvent & temp. & yield $^{b}$ \\
\hline 1 & 3 & 0 & $\mathrm{PhCN}$ & $60^{\circ} \mathrm{C}$ & quant \\
\hline 2 & 0.2 & 0 & $\mathrm{PhCN}$ & $60^{\circ} \mathrm{C}$ & $36 \%$ \\
\hline 3 & 0.2 & 0 & PhCN & $90^{\circ} \mathrm{C}$ & $40 \%$ \\
\hline 4 & 0.2 & 0.8 & $\mathrm{PhCN}$ & $90^{\circ} \mathrm{C}$ & $80 \%$ \\
\hline 5 & 0.1 & 0.8 & $\mathrm{PhCN}$ & $90^{\circ} \mathrm{C}$ & $59 \%$ \\
\hline 6 & 0.2 & 0.2 & $\mathrm{PhCN}$ & $90^{\circ} \mathrm{C}$ & $63 \%$ \\
\hline 7 & 0.2 & 0.8 & $\mathrm{MeCN}$ & $90^{\circ} \mathrm{C}$ & $32 \%$ \\
\hline 8 & 0.2 & 0.8 & DMF & $90{ }^{\circ} \mathrm{C}$ & $30 \%$ \\
\hline $9^{c}$ & 0.2 & 0.8 & PhCN & $90^{\circ} \mathrm{C}$ & $72 \%$ \\
\hline $10^{d}$ & 0.2 & 0.8 & $\mathrm{PhCN}$ & $90^{\circ} \mathrm{C}$ & $79 \%$ \\
\hline
\end{tabular}

aPerformed with $\mathbf{2 a}(0.050 \mathrm{mmol})$ and $\mathbf{1 a}(0.10 \mathrm{mmol})$ in solvent $(1.0 \mathrm{~mL}) .{ }^{\mathrm{b}}$ Determined by ${ }^{19} \mathrm{~F}$ NMR spectroscopy (benzotrifluoride was used as the internal standard). ${ }^{\mathrm{C}} \mathrm{CuBr}$ was used instead of $\mathrm{Cul} .{ }^{\mathrm{d}} \mathrm{CuCl}$ was used instead of $\mathrm{Cul}$. 
Table 2: Screening for diamine ligands ${ }^{a}$.

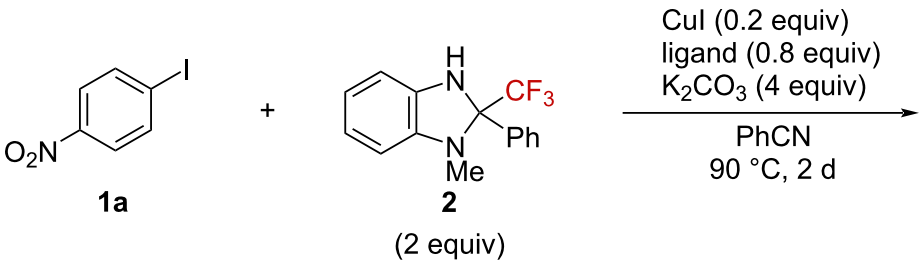

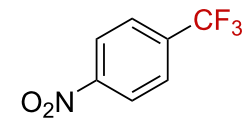

$3 \mathbf{a}$

(2 equiv)

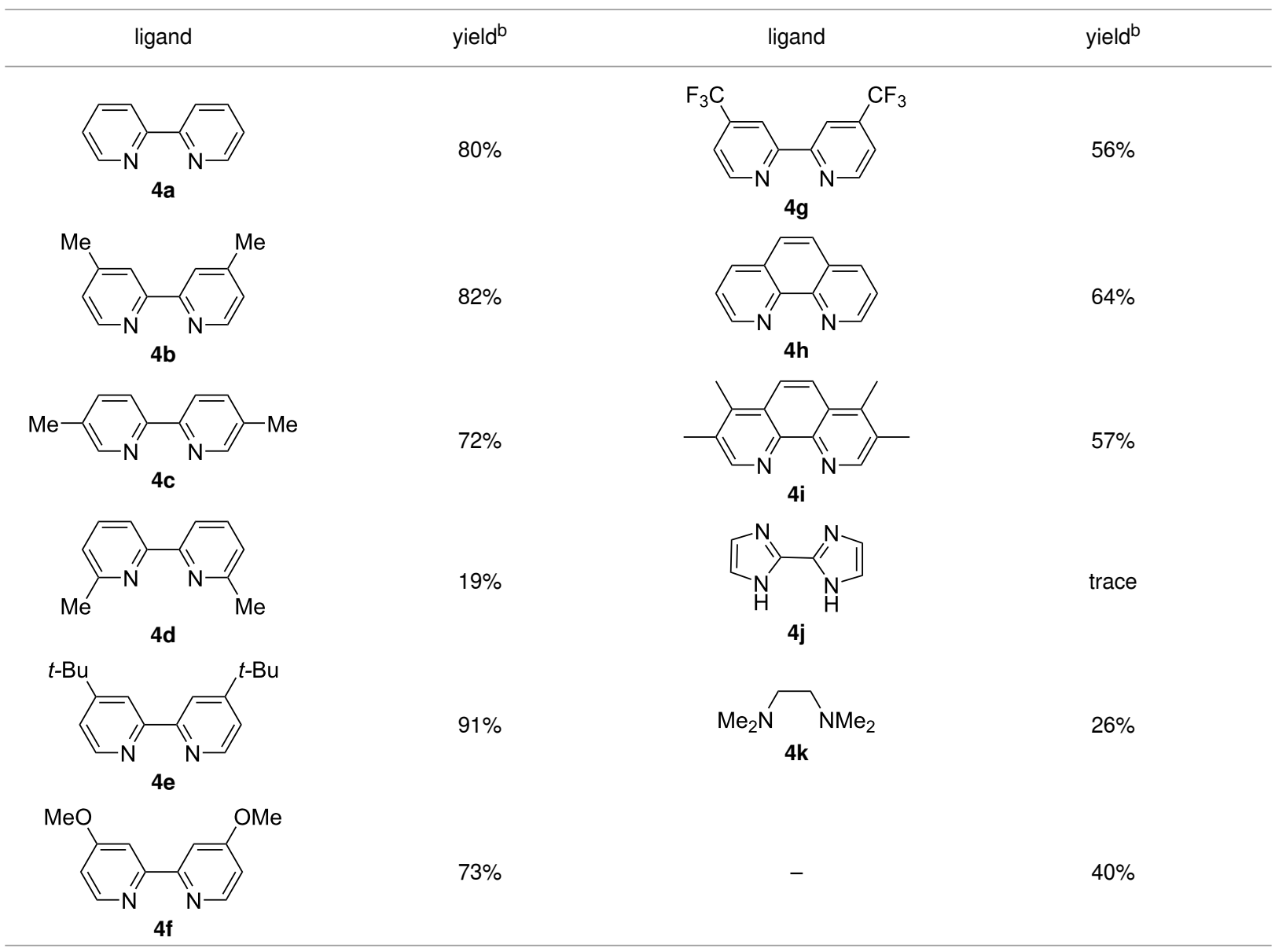

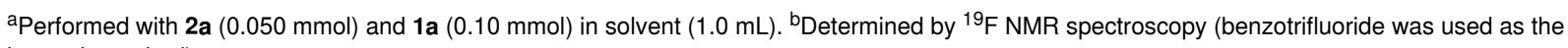
internal standard).

yields. Moreover, other electron-withdrawing ligands, i.e., phenanthroline derivatives (4h and $\mathbf{4 i}$ ), and electron-donating ligands such as 2,2 '-biimidazole $(\mathbf{4 j})$ and tetramethylethylenediamine (4k) gave inferior results.

We next screened for the generality of the reaction towards various substrates under the optimized conditions (Figure 2). Electron-deficient aryl iodides were well tolerated furnishing the corresponding trifluoromethylation products in high yields. Among the tested nitrophenyl derivatives, $p$ - and $o$-nitrophenyliodide gave the products in highest yields. In contrast, $m$-iodonitrobenzene afforded the trifluoromethylated product in a decreased yield of $35 \%$ due to the higher electron density of the meta-position compared to the ortho- and para-positions. Iodoarenes bearing other electron-withdrawing substituents, such as $p$-cyano, $p$-acetyl, and $p$-methoxycarbonyl, were also suitable and gave products $\mathbf{3 d}-\mathbf{f}$ in moderate to high yields. Furthermore, the presence of a formyl group was also tolerated in the reaction, and $p$-formyltrifluoromethylbenzene $(\mathbf{3 g})$ was obtained in $40 \%$ yield. However, the electron-rich substrate 2-methoxyiodobenzene $(\mathbf{1 h})$ gave product $\mathbf{3 h}$ in only a modest yield $(30 \%)$. 


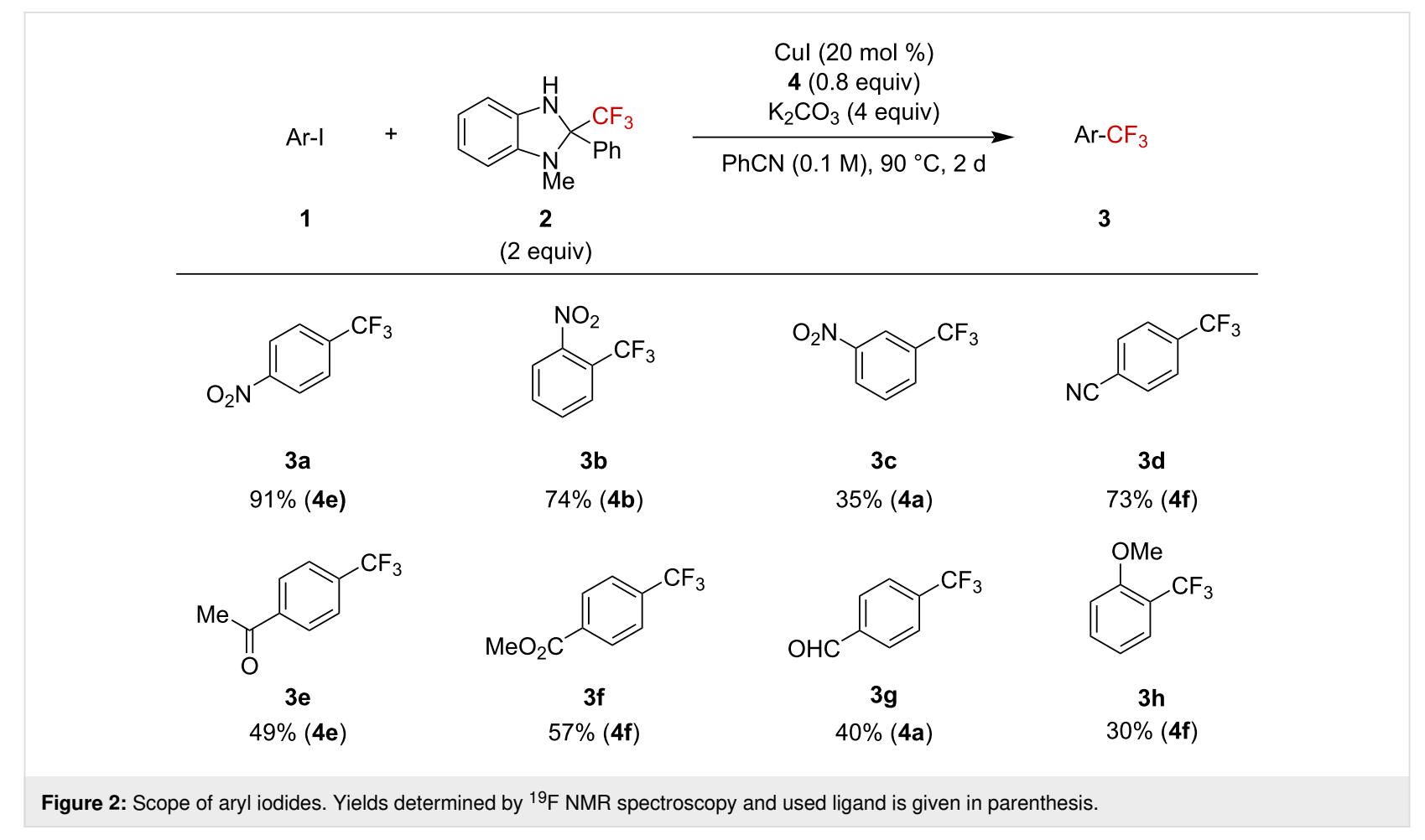

Heteroaryl iodides were also suitable substrates (Figure 3). 2-Iodopyridine (5a) gave the expected trifluoromethylation product $\mathbf{6 a}$ in $80 \%$ yield. 2-Iodoquinoline $(\mathbf{5 b})$ and 1-iodoisoquinoline (5c) were also suitable substrates to furnish desired products $\mathbf{6 b}$ and $\mathbf{6 c}$ in high yields. Furthermore, iodopyrazine was applicable to furnish $\mathbf{6 d}$ in $63 \%$ yield.

Finally, a mechanistic study of the reaction was carried out. First, the active species of the reaction was investigated by NMR analysis. The generation of $\mathrm{Cu}(\mathrm{I})-\mathrm{CF}_{3}$ was observed by mixing benzimidazoline 2 and $\mathrm{CuI}$ in $\mathrm{EtCN}$ at $90{ }^{\circ} \mathrm{C}$ (Figure $\mathrm{S} 1$, in Supporting Information File 1). Therefore, $\mathrm{CuI}$ and 2 generated $\mathrm{CuCF}_{3}$ species as the active species for the trifluoromethylation [24].

Then, the dependence of the conversion on the reaction time was estimated (Figure 4) and no induction period was observed. Although benzimidazoline 2 was completely consumed after $24 \mathrm{~h}$, the yield of the trifluoromethylation product continued to increase up to $48 \mathrm{~h}$. This suggests that product generation proceeded slower than the cleavage of the $\mathrm{C}-\mathrm{CF}_{3}$ bond of benzimidazoline.

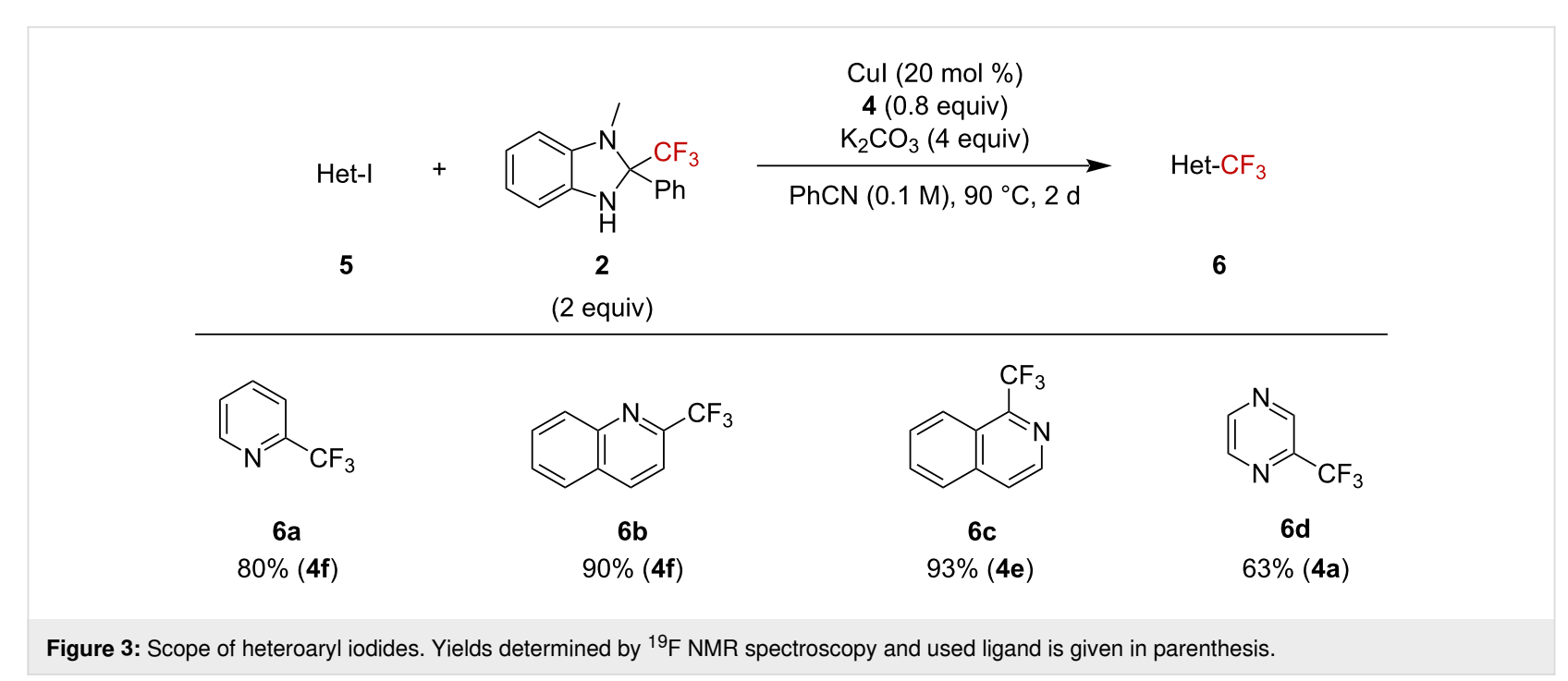


<smiles>O=[N+]([O-])c1ccc(I)cc1</smiles>

1a<smiles>CN1c2ccccc2NC1(c1ccccc1)C(F)(F)F</smiles>

2

( 2 equiv)

\section{Cul ( 0.2 equiv)}

2,2'-bipyridyl (0.8 equiv)

$\mathrm{K}_{2} \mathrm{CO}_{3}$ (4 equiv)

$\mathrm{PhCN}$

$90^{\circ} \mathrm{C}, 2 \mathrm{~d}$

$\mathrm{O}_{2} \mathrm{~N}$<smiles>O=[N+]([O-])c1ccc(C(F)(F)F)cc1</smiles>

3a

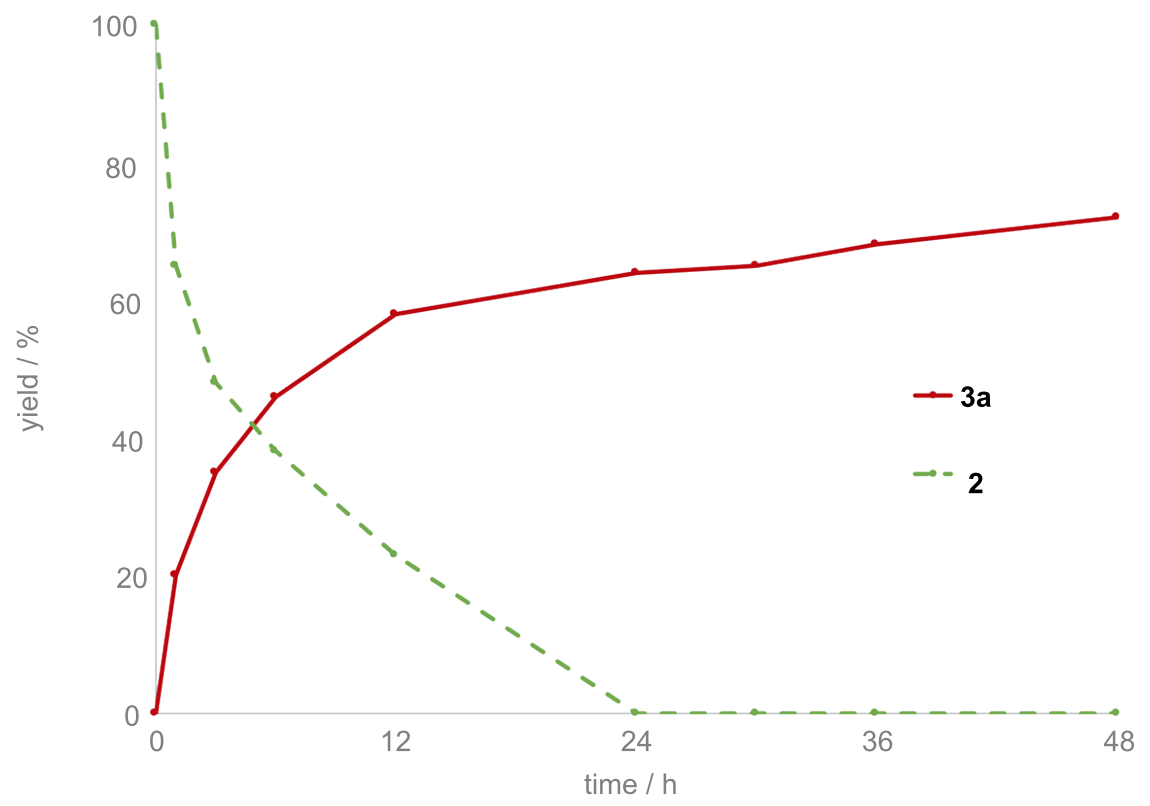

Figure 4: Time course of the trifluoromethylation reaction.

We propose a mechanism for the reaction, as shown in Figure 5. $\mathrm{The} \mathrm{Cu}(\mathrm{I})-\mathrm{CF}_{3}$ species, generated through the reaction of benzimidazoline 2 with $\mathrm{CuI}$ under basic conditions, underwent an oxidative addition reaction with the aryl iodide to generate a $\mathrm{Cu}$ (III) complex. A subsequent reductive elimination furnished the trifluoromethylarene and $\mathrm{Cu}(\mathrm{I})$. Because an electron-donating ligand was more effective than an electron-deficient one

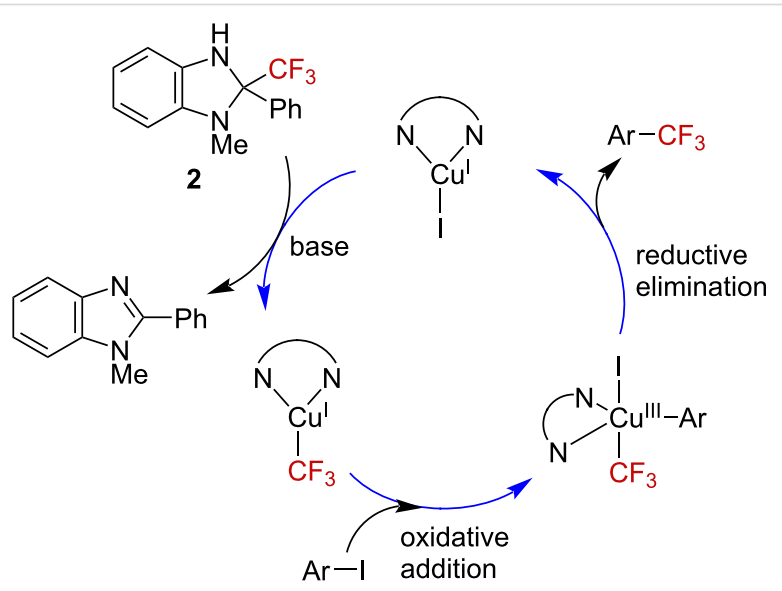

Figure 5: Proposed mechanism of the catalytic cycle.
(Table 2), and the reaction with benzimidazoline proceeded rapidly (Figure 4), the oxidative addition was suggested to be the rate-determining step.

\section{Conclusion}

In conclusion, we have developed a catalytic trifluoromethylation of aryl iodides by using trifluoromethylated benzimidazoline derivatives. The mechanistic study revealed that the oxidative addition was the rate-determining step of this reaction. 2-Phenyl-2-trifluoromethyl-1-methylbenzimidazoline is a novel type of trifluoromethylating reagents that might be useful for organic synthesis.

\section{Experimental}

General procedure of trifluoromethylation: Aryl iodide $\mathbf{1}$ (0.1 mmol), 2 (56 mg, $0.2 \mathrm{mmol}$ ), CuI (3.8 mg, $0.02 \mathrm{mmol}$ ), 2,2'-bipyridyl (12.5 mg, $0.08 \mathrm{mmol}$ ), and potassium carbonate (55.6 mg, $0.4 \mathrm{mmol})$ were mixed in benzonitrile $(1.0 \mathrm{~mL})$, and the mixture heated to $90{ }^{\circ} \mathrm{C}$. After $48 \mathrm{~h}$, hexafluorobenzene was added as an internal standard and the mixture analyzed by ${ }^{19}$ F NMR spectroscopy for the calculation of the NMR yield. Then, the crude products were purified by preparative TLC to give pure products 3 . 


\section{Supporting Information}

\section{Supporting Information File 1}

Details of screening experiments, synthetic procedures and characterization data of new compounds, and copies of spectra.

[https://www.beilstein-journals.org/bjoc/content/ supplementary/1860-5397-16-198-S1.pdf]

\section{Funding}

JSPS KAKENHI Grant Numbers JP17H03060, JP20H00380, and JP20H04826 (Hybrid Catalysis)

\section{ORCID® iDs}

Tatsuhiro Uchikura - https://orcid.org/0000-0002-0327-3675 Takahiko Akiyama - https://orcid.org/0000-0003-4709-4107

\section{References}

1. Wang, J.; Sánchez-Roselló, M.; Aceña, J. L.; del Pozo, C.; Sorochinsky, A. E.; Fustero, S.; Soloshonok, V. A.; Liu, H. Chem. Rev. 2014, 114, 2432-2506. doi:10.1021/cr4002879

2. Zhou, Y.; Wang, J.; Gu, Z.; Wang, S.; Zhu, W.; Aceña, J. L.; Soloshonok, V. A.; Izawa, K.; Liu, H. Chem. Rev. 2016, 116, 422-518. doi:10.1021/acs.chemrev.5b00392

3. Alonso, C.; Martínez de Marigorta, E.; Rubiales, G.; Palacios, F. Chem. Rev. 2015, 115, 1847-1935. doi:10.1021/cr500368h

4. Li, G.-b.; Zhang, C.; Song, C.; Ma, Y.-d. Beilstein J. Org. Chem. 2018, 14, 155-181. doi:10.3762/bjoc.14.11

5. Liu, X.; Xu, C.; Wang, M.; Liu, Q. Chem. Rev. 2015, 115, 683-730. doi:10.1021/cr400473a

6. Oishi, M.; Kondo, H.; Amii, H. Chem. Commun. 2009, 1909-1911. doi:10.1039/b823249k

7. Zhang, C. Org. Biomol. Chem. 2014, 12, 6580. doi:10.1039/c4ob00671b

8. Umemoto, T.; Zhang, B.; Zhu, T.; Zhou, X.; Zhang, P.; Hu, S.; Li, Y. J. Org. Chem. 2017, 82, 7708-7719. doi:10.1021/acs.joc.7b00669

9. Zanardi, A.; Novikov, M. A.; Martin, E.; Benet-Buchholz, J.; Grushin, V. V. J. Am. Chem. Soc. 2011, 133, 20901-20913. doi:10.1021/ja2081026

10. Chen, M.; Buchwald, S. L. Angew. Chem., Int. Ed. 2013, 52, 11628-11631. doi:10.1002/anie.201306094

11. Lin, X.; Hou, C.; Li, H.; Weng, Z. Chem. - Eur. J. 2016, 22, 2075-2084. doi:10.1002/chem.201504306

12. Zhang, C.-P.; Wang, Z.-L.; Chen, Q.-Y.; Zhang, C.-T.; Gu, Y.-C.; Xiao, J.-C. Angew. Chem., Int. Ed. 2011, 50, 1896-1900. doi:10.1002/anie.201006823

13. Li, X.; Zhao, J.; Zhang, L.; Hu, M.; Wang, L.; Hu, J. Org. Lett. 2015, 17 , 298-301. doi:10.1021/ol5034018

14. Negishi, K.; Aikawa, K.; Mikami, K. Eur. J. Org. Chem. 2016, 4099-4104. doi:10.1002/ejoc.201600711

15. Chen, Q.-Y.; Wu, S.-W. J. Chem. Soc., Chem. Commun. 1989 705-706. doi:10.1039/c39890000705

16. Kondo, H.; Oishi, M.; Fujikawa, K.; Amii, H. Adv. Synth. Catal. 2011, 353, 1247-1252. doi:10.1002/adsc.201000825
17. Knauber, T.; Arikan, F.; Röschenthaler, G.-V.; Gooßen, L. J. Chem. - Eur. J. 2011, 17, 2689-2697. doi:10.1002/chem.201002749

18. Li, Y.; Chen, T.; Wang, H.; Zhang, R.; Jin, K.; Wang, X.; Duan, C. Synlett 2011, 1713-1716. doi:10.1055/s-0030-1260930

19. Nakamura, Y.; Fujiu, M.; Murase, T.; Itoh, Y.; Serizawa, H.; Aikawa, K. Mikami, K. Beilstein J. Org. Chem. 2013, 9, 2404-2409. doi:10.3762/bjoc.9.277

20. Aikawa, K.; Nakamura, Y.; Yokota, Y.; Toya, W.; Mikami, K. Chem. - Eur. J. 2015, 21, 96-100. doi:10.1002/chem.201405677

21. Shimizu, N.; Kondo, H.; Oishi, M.; Fujikawa, K.; Komada, K.; Amii, H. Org. Synth. 2016, 93, 147-162. doi:10.15227/orgsyn.093.0147

22. Miyagawa, M.; Ishikawa, T.; Shinkai, K.; Akiyama, T. J. Fluorine Chem. 2019, 219, 29-31. doi:10.1016/j.jfluchem.2018.12.006

23. The bipyridyl ligands stabilize the copper(I) catalyst for catalytic reaction (see ref. [6]).

24. From the examination of an aryl group at the 2-position of benzimidazolines, electron-rich moieties were more reactive than electron-deficient ones (Table S5, see Supporting Information File 1). These results suggest that an oxidative addition step proceeds by nucleophilic process.

\section{License and Terms}

This is an Open Access article under the terms of the Creative Commons Attribution License (https://creativecommons.org/licenses/by/4.0). Please note that the reuse, redistribution and reproduction in particular requires that the authors and source are credited.

The license is subject to the Beilstein Journal of Organic Chemistry terms and conditions: (https://www.beilstein-journals.org/bjoc)

The definitive version of this article is the electronic one which can be found at: https://doi.org/10.3762/bjoc. 16.198 